\title{
Asthma is not a risk factor for the severity of SARS-CoV-2 infection in the Mexican population
}

\author{
Jaime Morales-Romero $^{1}$ and Martín Bedolla-Barajas ${ }^{2}$ \\ ${ }^{1}$ Universidad Veracruzana \\ ${ }^{2}$ Nuevo Hospital Civil de Guadalajara
}

November 30, 2020

\begin{abstract}
Background. Asthma does not seem to confer a risk for developing a disease caused by 2019 novel coronavirus (COVID-19). The aim of this study was to assess the association between asthma and severity of COVID-19 in the Mexican population. Methods. In a cross-sectional study, we analyzed the data of the population in Mexico who underwent a test to detect COVID-19 from February 27 to June 21, 2020. The primary outcomes were hospitalization, pneumonia, endotracheal intubation, and death related to COVID-19 in patients with asthma. Results. Asthma was associated with a lower risk of hospitalization $(\mathrm{OR}=0.71$, $95 \%$ CI 0.66 to 0.76 ), lower risk of pneumonia ( $\mathrm{OR}=0.75,95 \%$ CI 0.69 to 0.81 ), and lower risk of endotracheal intubation $(\mathrm{OR}=0.79,95 \%$ CI 0.63 to 0.98$)$. In addition, asthma decreased the risk of dying from COVID-19 (OR $=0.73,95 \% \mathrm{CI} 0.65$ to 0.82$)$. In a subgroup analysis, the same trend was observed in patients who required hospitalization $(\mathrm{OR}=0.79,95 \% \mathrm{CI}$ 0.69 to 0.90 ); while in non-hospitalized patients, associations were inconsistent according to the covariates introduced to the models. There was no association between asthma and death in patients admitted to the intensive care unit (ICU); however, in hospitalized patients who did not require ICU management, asthma significantly reduced the risk of dying. Conclusion. Our results suggest that compared to patients without asthma, patients with asthma are less likely to require hospitalization, develop pneumonia, be intubated endotracheally, or die from COVID-19.
\end{abstract}

\section{Hosted file}

Manuscript.pdf available at https://authorea.com/users/380015/articles/496152-asthma-is-nota-risk-factor-for-the-severity-of-sars-cov-2-infection-in-the-mexican-population 